\title{
Assessing the Risks of Topically Applied dsRNA-Based Products to Non-target Arthropods
}

\author{
Jörg Romeis ${ }^{1 *}$ and Franco Widmer ${ }^{2}$ \\ ${ }^{1}$ Research Division Agroecology and Environment, Agroscope, Zurich, Switzerland, ${ }^{2}$ Competence Division Method \\ Development and Analytics, Agroscope, Zurich, Switzerland
}

\section{OPEN ACCESS}

Edited by:

Michael L. Mendelsohn, United States Environmental

Protection Agency (EPA), United States

Reviewed by:

Yiguo Hong,

Hangzhou Normal University, China Alasdair Nisbet,

Moredun Research Institute, United Kingdom

*Correspondence: Jörg Romeis

joerg.romeis@agroscope.admin.ch

Specialty section:

This article was submitted to Plant Microbe Interactions, a section of the journal Frontiers in Plant Science

Received: 08 October 2019 Accepted: 30 April 2020

Published: 04 June 2020

Citation:

Romeis $J$ and Widmer F (2020) Assessing the Risks of Topically Applied dsRNA-Based Products

to Non-target Arthropods.

Front. Plant Sci. 11:679

doi: 10.3389/fp/s.2020.00679
RNA interference (RNAi) is a powerful technology that offers new opportunities for pest control through silencing of genes that are essential for the survival of arthropod pests. The approach relies on sequence-specificity of applied double-stranded (ds) RNA that can be designed to have a very narrow spectrum of both the target gene product (RNA) as well as the target organism, and thus allowing highly targeted pest control. Successful RNAi has been reported from a number of arthropod species belonging to various orders. Pest control may be achieved by applying dsRNA as foliar sprays. One of the main concerns related to the use of dsRNA is adverse environmental effects particularly on valued non-target species. Arthropods form an important part of the biodiversity in agricultural landscapes and contribute important ecosystem services. Consequently, environmental risk assessment (ERA) for potential impacts that plant protection products may have on valued non-target arthropods is legally required prior to their placement on the market. We describe how problem formulation can be used to set the context and to develop plausible pathways on how the application of dsRNA-based products could harm valued non-target arthropod species, such as those contributing to biological pest control. The current knowledge regarding the exposure to and the hazard posed by dsRNA in spray products for non-target arthropods is reviewed and suggestions are provided on how to select the most suitable test species and to conduct laboratorybased toxicity studies that provide robust, reliable and interpretable results to support the ERA.

Keywords: ecosystem services, environmental risk assessment, hazard, exposure, pathways to harm, problem formulation, species selection, tiered risk assessment

\section{INTRODUCTION}

RNA interference (RNAi) is a mechanism of gene silencing present in most eukaryote organism to regulate gene expression (Hannon, 2002). The silencing effect can be triggered by double-stranded RNA (dsRNA), is RNA sequence-specific, and makes use of the core RNAi machinery to degrade complementary RNA molecules. RNAi thus provides a tool that can be designed to affect and control insect pests in a highly specific manner by targeting genes that are essential for the survival of the species (Xue et al., 2012; Burand and Hunter, 2013; Zhang et al., 2017; Liu et al., 2020). In an agricultural context the technology may also be deployed to increase the sensitivity of pests or 
vectors to chemical insecticides (e.g., Killiny et al., 2014; Bona et al., 2016) or to protect beneficial species from viral diseases (Vogel et al., 2019).

For application as a pest control tool, the active dsRNA molecule has to enter and affect the target pest. This can be achieved by two main ways of application. First, dsRNA can be produced in planta, which requires genetic engineering (GE) of the plant. The first product of that kind has recently been approved by US regulators in June $2017^{1}$. This particular GE maize event (MON87411) produces a dsRNA targeting the Snf7 protein in the Western Corn Rootworm, Diabrotica virgifera virgifera (Coleoptera: Chrysomelidae), which is crucial for the transport of transmembrane proteins. Suppression of the Snf7 gene leads to increased larval mortality and consequently to reduced root damage (Bolognesi et al., 2012). The RNAi trait is combined with the Cry3Bb1 protein for improved target pest control and resistance management (Levine et al., 2015; Head et al., 2017). Second, the dsRNA molecules can be applied externally, for example in irrigation water or through trunk injections (Hunter et al., 2012; Li et al., 2015a; Niu et al., 2018; Kunte et al., 2020), in food-baits (Zhou et al., 2008; Zhang et al., 2010), by using delivery systems such as micro-organisms, viruses, nanocarriers (Kunte et al., 2020; Vogel et al., 2019), or topically as spray applications (San Miguel and Scott, 2016).

Two major challenges have been identified for implementing the RNAi-based technology in pest control. First, the target organisms have to ingest intact and biologically active dsRNA molecules in order to trigger an RNAi response. While RNAi has been observed in a number of insect species belonging to various orders, the effectiveness of dietary RNAi (derived from ingested dsRNA) is less clear (Baum and Roberts, 2014). Second, there is evidence that resistance is not developed against a specific dsRNA molecule but to components in the dsRNA uptake machinery in the intestinal tract or in the dsRNA processing machinery. For example, Khajuria et al. (2018) demonstrated for D. v. virgifera, that resistance to dsRNA targeting $S n f 7$, was due to the fact that cellular uptake was prevented.

Despite those challenges, effective dsRNA-based spray products that cause specific toxic effects on selected arthropod pest species are expected within the next few years (Hogervorst et al., 2018; Taning et al., 2020) and our perspective will focus on this method of application.

\section{ENVIRONMENTAL RISK ASSESSMENT}

As pesticides, dsRNA-based sprays are regulated stressors that have to pass an environmental risk assessment (ERA) before being commercially released to ensure that their use causes no unacceptable harm to the environment. Given the novel mode of action, the regulatory and data requirements are discussed internationally (Auer and Frederick, 2009; US EPA, 2014; Roberts et al., 2015).

Early in the ERA, in a step called "Problem Formulation," the protection goals set by environmental policy need to be identified,

\footnotetext{
${ }^{1}$ https://www.epa.gov/pesticide-registration/epa-registers-innovative-toolcontrol-corn-rootworm
}

and operational protection goals and plausible pathways on how the stressor of concern could harm those protection goals (i.e., pathways to harm) are defined (Raybould, 2006; Gray, 2012; Craig et al., 2017; Raybould et al., 2019). Based on these "Pathways to Harm," testable risk hypotheses can be derived, existing relevant information is collected and required data are identified. The aim of this process is to ensure that any decision taken is made in a traceable and transparent manner. While experience has been gained with applying problem formulation to the ERA of GE plants, the concept is equally applicable to other stressors, including dsRNA-based pesticides (Devos et al., 2019; Raybould and Burns, 2020).

For plant protection products such as dsRNA-based sprays, "biodiversity" is an important environmental protection goal, which is found in policies of most jurisdictions. However, this term is very general and thus specific (operational) protection goals need to be defined that can then be addressed in the scientific risk assessment. Such operational protection goals delineate the components of the environment that are valued and should be protected, including details on the location, the exact time period, and the maximum tolerable impact (Nienstedt et al., 2012; Sanvido et al., 2012; Devos et al., 2015). In this respect, it has been proposed to categorize biodiversity in categories of valued ecosystem services ("ecosystem service concept") as defined for example in the Millennium Ecosystem assessment (Millennium Ecosystem Assessment [MEA], 2005; Gilioli et al., 2014; Devos et al., 2015; European Food Safety Authority Scientific Committee, 2016; Maltby et al., 2017a,b). In the case of arthropods this includes regulating services (e.g., biological pest control, pollination), cultural services (e.g., protected species), and supporting services (e.g., arthropods that contribute to nutrient cycling).

Once the components of the environment to be protected are identified, plausible pathways to harm can be constructed. In Figure 1 such pathways to harm are defined for the protection goal "biological pest control" that is provided by predators and parasitoids, which may be affected by the application of a dsRNAbased spray. For a spray product to cause harm to the protection goal, a line of events or steps has to occur. If one can conclude with high certainty that one or more of the steps are unlikely to happen, the pathway is interrupted, which allows to conclude that the risk to biological control is negligible (Raybould et al., 2019). Thus the different steps can be tested or assessed in the ERA to characterize the risk. In principle the steps either relate to exposure, the likelihood that non-target species actually ingest sufficient amounts of biological active dsRNA, or hazard, which relates to the sensitivity of the non-target species to dietary RNAi. These two aspects of the risk equation will be discussed in the following sections.

\section{EXPOSURE OF NON-TARGET ARTHROPODS TO dSRNA IN SPRAY PRODUCTS}

Non-target arthropod species could directly be exposed to dsRNA in spray products when consuming treated plant material in 


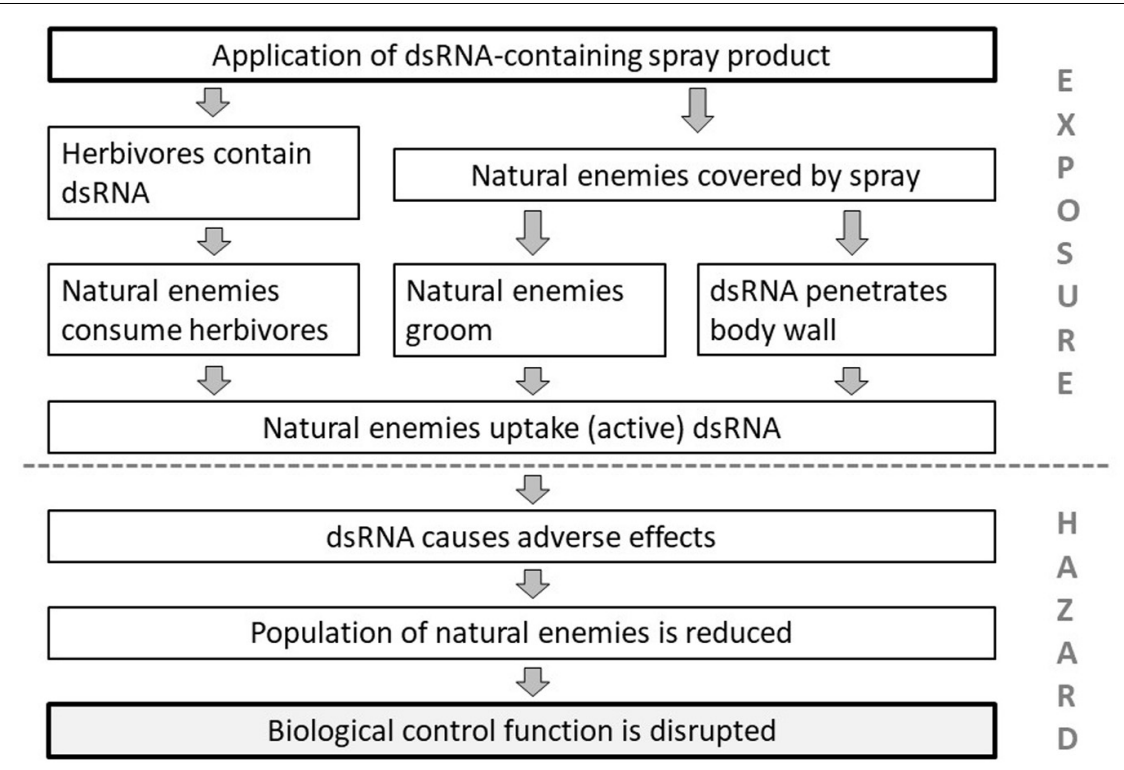

FIGURE 1 | Plausible pathways to harm. Steps on how the application of a dsRNA-based spray insecticide could cause harm to the protection goal of "biological pest control" by affecting arthropod natural enemies (predators and parasitoids).

the field or outside the field in case of spray-drift, through contact with soil and water or topical application and indirect when feeding on arthropods that have been exposed. While the plant cuticle and also the cell walls limit the uptake of spray-applied dsRNA into the plants, there is some evidence for uptake and transport in the vascular system of bioactive dsRNA (Koch et al., 2016), which can be further enhanced by high pressure spraying (Dalakouras et al., 2016) or particular carriers (Mitter et al., 2017).

In general, stability of naked dsRNA in the environment is very low. Degradation of dsRNA within 2 days has been reported for soil and aquatic environments (Dubelman et al., 2014; Fischer et al., 2016, 2017; Bachman et al., 2020) although partial adsorption to soil particles will also play a role (Parker et al., 2019). Degradation appears neither to be affected by dose (Dubelman et al., 2014) nor by length or structure of the dsRNA molecule (Fischer et al., 2016). There is some indication that degradation of dsRNA molecules is reduced on plant surfaces (Tenllado et al., 2004; San Miguel and Scott, 2016). The persistence of dsRNA in formulated spray products is difficult to predict since the active ingredient is likely to be stabilized to prevent abiotic and biotic degradation. For example, Mitter et al. (2017) recently demonstrated that pathogen-specific dsRNA targeting plant viruses could be detected for more than 30 days after application when loaded on layered double hydroxide clay nanosheets. Thus, the formulation in which the molecule is applied has to be considered in the exposure assessment (Bachman et al., 2020).

The routes and duration of non-target organism exposure to dsRNA in sprayed products will depend on a number of factors, including: (1) application rate of the active ingredient, (2) application timing, (3) application method, (4) number of applications, (5) off-site movement of applied dsRNA, and (6) stability and persistence of exogenously applied dsRNA following application (US EPA, 2014).

For predators and parasitoids we have identified three main routes of exposure (Figure 1). The first, and the most likely route is indirect, through their prey or hosts. Herbivores can be covered by the spray or ingest the dsRNA when feeding on the treated plants. It remains to be confirmed, however, that dsRNA ingested by a herbivore is still biologically active when passed on to the next trophic level. To our knowledge, cross-species transfer of biologically active dsRNA has only been reported in one study, i.e., between honey bees (Apis mellifera, Hymenoptera: Apidae) and parasitic mites, Varroa destructor (Acari: Varroidae) (Garbian et al., 2012). The second potential route of exposure of natural enemies is through the insects' integument. There is some evidence that dsRNA applied topically can penetrate the insect's body wall, i.e., via the inter-segmental membranes, and cause an RNAi response. The first case of this nature was reported for Aedes aegypti (Diptera: Culicidae) by Pridgeon et al. (2008). Penetration has also been demonstrated for larvae of Ostrinia furnacalis (Lepidoptera: Crambidae) using fluorescent dsRNA albeit at very high concentrations of $0.5 \mu \mathrm{l}$ of $0.5 \mu \mathrm{g} / \mu \mathrm{l}$ fluorescent labeled dsRNA per larva (Wang et al., 2011). However, it is difficult in such topical application studies to rule out that the dsRNA molecules entered the body through the spiracles rather than through the integument. However, there is evidence that the penetration efficiency can be enhanced by altering the formulation in which the dsRNA is applied. For example, in the case of the soybean aphid Aphis glycines (Hemiptera: Aphididae) penetration efficiency was significantly enhanced using a nanocarrier in combination with an amphiphilic periphery detergent to increase the attachment of the droplets to the insect cuticula (Zheng et al., 2019). In a recent study, Niu et al. (2019) observed the uptake of dsRNA topically 
applied to Acyrthosiphon pisum (Hemiptera: Aphididae) within $12 \mathrm{~min}$. As a third route of exposure, insects might also ingest the molecule during grooming after they have been covered by dsRNA after a spray application. While some predators also feed on green plant tissue when prey is scarce (Lundgren, 2009) we regard this route of exposure as negligible.

Dietary uptake of dsRNA, does not necessarily mean that the molecule is still biologically active. Extraoral digestion is know from many predatory arthropods including spiders, lacewing larvae and predatory bugs (Cohen, 1998; Zhu et al., 2016; Walter et al., 2017). According to Cohen (1995) at least 79\% of predaceous land-dwelling arthropods use extra-oral digestion. For example, it has been demonstrated for the plant bug Lygus lineolaris (Hemiptera: Miridae) that dsRNA molecules are completely digested to monomers by endonucleases in the saliva prior to ingestion (Allen and Walker, 2012).

\section{HAZARD POSED BY dsRNA}

In principle, ingested dsRNA can pose a hazard to a non-target arthropod in two ways, i.e., sequence-specific and sequenceunspecific. Mechanisms that have been suggested as a cause of sequence-unspecific effects of ingested dsRNA are first, the induction of a general immune response since RNAi is a component of the innate antiviral immunity response and second, a saturation of the RNAi machinery, i.e., the dsRNA processing enzymes (Dillin, 2003; Christiaens et al., 2018a). While saturation of the RNAi machinery has been observed in animals (mice and cell cultures) at high doses (US EPA, 2014), it has not yet been reported in arthropods (Miller et al., 2012; Christiaens et al., 2018a). DsRNA-triggered general immune responses, e.g., the upregulation of dsRNAase, have been observed in honey bees (Apis mellifera, Hymenoptera: Apidae) (Flenniken and Andino, 2013; Brutscher et al., 2017), bumble bees (Bombus terrestris, Hymenoptera: Apidae) (Piot et al., 2015), and the silkworm (Liu et al., 2013). There is evidence from feeding studies that high doses of dsRNA can boost a sequence-unspecific response in ladybird beetles (Coleoptera: Coccinellidae) (Haller et al., 2019). But comparable doses (of the same construct) did not cause such effects in other arthropod species studied (Pan et al., 2016; Vélez et al., 2016). Sequenceunspecific effects have also been observed for dsGFP in honey bees, A. mellifera, in feeding and injection studies (Jarosch and Moritz, 2012; Nunes et al., 2013). In summary, while there is no evidence that dsRNA can cause a saturation of the RNAi machinery in arthropods, high doses of dsRNA may affect the fitness of non-target arthropod species in a sequence-unspecific way through a stimulation of the immune system. Consequently, from an ERA perspective, non- and off-target effects of the dsRNA that are sequence specific are of much more concern and will be the focus of the following description.

After ingestion of dsRNA molecules, a successful RNAi response depends on a variety of factors that will be discussed below, including: stability of dsRNA in the gut (affected by gut $\mathrm{pH}$ and nucleases), dsRNA length and concentration, target gene, arthropod species and the life-stage exposed (Katoch et al., 2013;
Scott et al., 2013; Davis-Vogel et al., 2018; Cooper et al., 2019; Kunte et al., 2020).

Once an insect has ingested dsRNA and the molecule has been taken up by the cells, the endonuclease Dicer cuts the molecule into short interfering RNAs (siRNA) of a length of 20-25 bp that are integrated into the RNA-induced silencing complex (RISC) (Hannon, 2002). Subsequently RISC facilitates the targeting and the endonucleolytic attack on mRNAs with sequence identity to the dsRNA (Hannon, 2002). The pre-requisite for a successful RNAi response is thus sequence identity between at least some of the siRNAs derived from the dsRNA and the target mRNA of the insect pest (Scott et al., 2013). Consequently, length of the dsRNA affects the effectiveness of the RNAi response, as longer molecules yield larger populations of overlapping siRNA molecules ranging in size and sequence (Baum et al., 2007; Bolognesi et al., 2012; Miller et al., 2012; Li et al., 2015b; Nandety et al., 2015). An injection study with Tribolium castaneum (Coleoptera: Tenebrionidae) suggests that the size of the dsRNA molecule also affects the duration of the RNAi response, event though the mechanism involved remains unclear (Miller et al., 2012). There is evidence that contiguous sequence matches of $\geq 21 \mathrm{nt}$ of the dsRNA to the target gene are necessary for dsRNA to be biologically active in insects (Bachman et al., 2013, 2016; Roberts et al., 2015) and it has been reported that even a single 21 nt sequence match can induce effects (Bolognesi et al., 2012). It has to be noted, however, that RNAi has been demonstrated to occur at sequence length as short as 15 bp (Powell et al., 2017). Still uncertain is the extent of sequence mismatch that has to be present in order to prevent dsRNA-derived siRNAs. Because siRNA molecules can inhibit translation of transcripts even when mismatches occur, the threshold for concern about non-target effects could be less than $100 \%$ sequence identity (Scott et al., 2013). For providing the evidence that any observed effect is due to specific gene silencing, it is necessary to support the feeding assays by determination of transcript levels with RTqPCR. This, however, poses the challenge of identifying suitable reference or housekeeping genes to calculate relative transcript levels. Furthermore, the effect of RNAi on the protein may not be well correlated to the level of transcript suppression (Scott et al., 2013).

While functional RNAi has been reported from a number of insect species belonging to various orders, the impact of dietary RNAi is more limited (Baum and Roberts, 2014). While many insects have been found to be susceptible to dietary RNAi (Belles, 2010), large differences in sensitivity have been reported across taxa (Whangbo and Hunter, 2008; Terenius et al., 2011; Cooper et al., 2019). For example, feeding studies where solutions containing dsRNA were provided demonstrated that many Coleoptera show a $\mathrm{LC}_{50}$ at dsRNA concentrations from 1 to $-10 \mathrm{ppb}$, while effects are seen in Diptera at 10-500 ppm, and in Lepidoptera/Hemiptera at $>1000$ ppm (Baum and Roberts, 2014). It has to be noted, however, that sensitivity to dietary RNAi can vary significantly among even closely related species as has been demonstrated for sweetpotato weevils, Cylas spp. (Coleoptera: Brentidae) (Christiaens et al., 2016; Prentice et al., 2017). It can even vary between strains/populations of a particular species as has for example been reported for Locusta migratoria 
(Orthoptera: Acrididae) (Sugahara et al., 2017) and T. castaneum (Kitzmann et al., 2013; Spit et al., 2017).

Degradation of the dsRNA after ingestion or uptake is a major factor affecting the exposure of non-target species to bioactive dsRNA molecules and thus the effectivity of RNAi (Wang et al., 2016). Gut pH is important as it affects the stability of the ingested dsRNA molecules. Since RNA is most stable at pH of 4.0-5.0, the slightly acidic midguts of Coleoptera and Hemiptera ( $\mathrm{pH}$ around 5) support dsRNA stability. In contrast, stability is low in the alkaline guts of Orthoptera, Diptera and Hymenoptera and in particular in the highly alkaline guts of Lepidoptera $(\mathrm{pH}>8.0)$ (Cooper et al., 2019). In addition, dsRNA can be degraded by nucleases in the insect guts as has for example been reported for Bombyx mori (Lepidoptera: Bombycidae) (Arimatsu et al., 2007; Liu et al., 2012, 2013) and the desert locust, Schistocerca gregaria (Orthoptera: Acrididae) (Wynant et al., 2014). Degradation of dsRNA in the gut also explains the relatively low sensitivity of Cylas puncticollis to dietary RNAi when compared to the closely related C. brunneus (both Coleoptera: Brentidae) (Christiaens et al., 2016; Prentice et al., 2017). After uptake, dsRNA can be degraded by nucleases in the haemolymph (Wang et al., 2016) as has for example been reported for Manduca sexta (Lepidoptera: Sphingidae) (Garbutt et al., 2013) and A. pisum (Christiaens et al., 2014).

To enhance the stability of the ingested dsRNA, to prevent degradation by nucleases and to enhance cellular uptake, various carriers have successfully been deployed (Yu et al., 2013; Christiaens et al., 2018b; Kunte et al., 2020; Vogel et al., 2019). This includes lipid-based encapsulations (Whyard et al., 2009; Taning et al., 2016; Lin et al., 2017), cell-penetrating peptides (Gillet et al., 2017), polymers (Zhang et al., 2010; Christiaens et al., 2018a), and other nanoparticles (He et al., 2013; Das et al., 2015). In addition the RNAi response can be enhanced by co-delivery of nuclease-specific dsRNA (Spit et al., 2017; Cooper et al., 2019). Thus, the formulation in which the dsRNA is provided also has to be considered when judging the hazardous potential of the molecule to non-target species.

\section{SELECTION OF TEST SPECIES FOR NON-TARGET STUDIES}

Since not all valued non-target arthropods present in the receiving environment that are potentially exposed to the dsRNAbased product can be tested, surrogate (test) species need to be selected for toxicity studies to support the non-target risk assessment. The following description focuses on the selection of test species to detect sequence-specific effects caused by the particular dsRNA molecule under consideration.

Non-target testing of chemical pesticides has a long history in Europe. At the initial stage, only 2 species are tested under worstcase exposure conditions, i.e., the predatory mite Typhlodromus pyri (Acari: Phytoseiidae) and the parasitic wasp Aphidius rhopalosiphi (Hymenoptera: Braconidae) (Candolfi et al., 2001). The two species were selected as indicators since sensitivity analyses revealed that they are the most sensitive species to most classes of pesticides (Candolfi et al., 1999; Vogt, 2000).
Consequently, by testing those species predictions of effects on other non-target arthropods can be made with high confidence (Candolfi et al., 1999). Only if adverse effects above a certain threshold are detected for those species and unacceptable risk can thus not be excluded additional tests with other beneficial species are indicated. These include Orius laevigatus (Hemiptera: Anthocoridae), Chrysoperla carnea (Neuroptera: Chrysopidae), Coccinella septempunctata (Coleoptera: Coccinellidae), and Aleochara bilineata (Coleoptera: Staphilinidae). These species were selected because they are commercially available, amenable to testing in the laboratory, reliable test protocols exist, they provide sufficient phylogenetic and functional diversity, and common in agricultural fields (Barrett et al., 1994; Candolfi et al., 2001). In addition to testing predators and parasitoids, most regulatory jurisdictions (e.g., European Commission [EC], 2002), require testing of honey bees (A. mellifera) and soil organisms [Folsomia candida (Collembola: Isotomidae) or Hypoaspis aculeifer (Acari: Gamasidae)], if exposure of the latter is anticipated.

This common set of surrogate test species, however, is not suitable to assess non-target effects caused by dsRNA-based spray products because the initial two indicator species were selected for their sensitivity to chemical pesticides but are unlikely to be the most sensitive species for the majority of dsRNA molecules. Consequently it would be more suitable to apply the approach for non-target risk assessment as is conducted for GE plants expressing insecticidal proteins, such as Bt crops expressing Cry or VIP proteins from Bacillus thuringiensis. The ERA for GE plants is conducted case-by-case and consequently the most appropriate non-target species can be selected for each plant/trait combination. It has been proposed to base the selection of test species for laboratory studies on three main criteria (Romeis et al., 2013):

(i) Sensitivity: species should be the most likely to be sensitive to the stressor under consideration based on the known spectrum of activity, its mode of action, and the phylogenetic relatedness of the test and target species.

(ii) Relevance: species should be representative of valued taxa or functional groups that are most likely to be exposed to the stressor in the field. Organisms that contribute to important ecosystem service and are considered relevant have been identified for a number of field crops (e.g., Meissle et al., 2012; Romeis et al., 2014; Riedel et al., 2016; Li et al., 2017).

(iii) Availability and reliability: suitable life-stages of the test species must be obtainable in sufficient quantity and quality, and validated test protocols must be available that allow consistent detection of adverse effects on ecologically relevant parameters. Lists of above-ground, below-ground, and aquatic species that are available and amenable for testing have been published (e.g., Candolfi et al., 2000; Römbke et al., 2010; Romeis et al., 2013; Carstens et al., 2012; Li et al., 2017).

The above listed criteria are also key elements of other test species selection approaches that have for example been published by Todd et al. (2008) and Hilbeck et al. (2014).

While the criteria (ii) and (iii) are relative generic or cropspecific, criteria (i) needs to be addressed specifically for each stressor under consideration. To increase the robustness and 
reliability of the non-target risk assessment the species most likely to be sensitive (= affected) to a particular dsRNA should be selected. This includes considerations of the gene or gene family that is targeted and the knowledge about the sensitivity of certain taxa to dietary RNAi in general. The phylogenetic relationship of the non-target organisms to the target pest should also be considered, as there is evidence that, in general, species closely related to the target organism are more likely to be susceptible to the dsRNA than distantly related species (Whyard et al., 2009; Bachman et al., 2013, 2016; US EPA, 2014; Roberts et al., 2015).

Since the RNAi response is sequence specific, bioinformatics can help predicting the species most likely affected that could then be used in feeding studies (Bachman et al., 2013, 2016). However, it has to be recognized that the presence of sequence homologies between the dsRNA molecule and the genome of the non-target species does not necessarily indicate sensitivity of an organisms. For example, the springtail Sinella curviseta (Collembola: Entomobryidae) shares a total of six $21 \mathrm{nt}$ long matches with the dsRNA targeting the vATPase $A$ in D. $v$. virgifera. However, the organism was not adversely affected in laboratory feeding studies (Pan et al., 2016). In cases where for some reason (species that are rare, protected or difficult to rear), bioinformatics may, however, be the only way to "test" the species (Bachman et al., 2016). Bioinformatics could also help predicting off-target effects. However, currently we lack genomic data for most non-target species. It would be useful to have more genome data available for model non-target species that actually play a role in agricultural production systems to effectively apply bioinformatics to the NTO risk assessment (Casacuberta et al., 2015; Fletcher et al., 2020).

\section{DESIGN AND IMPLEMENTATION OF NON-TARGET LABORATORY TOXICITY STUDIES}

The established test protocols published by the West Palaearctic Regional Section of the International Society for Biological and Integrated Control (IOBC/WPRS; Candolfi et al., 2000) or by the European and Mediterranean Plant Protection Organization $(\mathrm{EPPO})^{2}$ for early-tier laboratory toxicity studies for chemical insecticides are based on contact toxicity. Those test protocols thus do not allow assessing the non-target effects of dsRNA for which oral uptake is the most important route of exposure. The lack of standardized test protocols addressing the oral route of exposure and to detect effects resulting from novel modes of action has recently been pointed out by the Panel on Plant Protection Products and their Residues of European Food Safety Authority (2015) even though RNAi was not specifically mentioned.

However, experience is available with gut-active insecticidal proteins such as the Cry and VIP proteins from B. thuringiensis. Guidance exists on how to design and perform laboratory feeding studies with such proteins to provide high quality, reliable and robust data (Romeis et al., 2011; De Schrijver et al., 2016).

${ }^{2}$ https://ppl.eppo.int/standards/side_effects
When designing a non-target laboratory study the following main criteria should be considered (Romeis et al., 2011): (i) Test substance characterization and formulation; (ii) Method of delivery; (iii) Concentration/dose; (iv) Measurement endpoints; (v) Test duration; (vi) Control treatments; (vii) Statistical considerations.

Since the formulation in which the dsRNA is provided has a strong effect on the dsRNA uptake and the strength of the RNAi response in arthropods (as discussed above) care should be taken that the test substance is provided in a realistic formulation.

It is generally considered that toxicity of insecticidal compounds such as chemical insecticides and Cry proteins from Bt increases with increasing concentration in which they are delivered. Thus safety is added to the non-target studies by testing unrealistically high concentrations of the stressor of concern to provide a margin of safety and to account for possible intraand interspecific variability from the use of a surrogate test species. Definition of the concentrations to be tested poses some challenges for different reasons. First, the length of the dsRNA affects the effectiveness to trigger an RNAi response (Bolognesi et al., 2012; Miller et al., 2012), thus the margins of safety may vary between constructs. Second, there is evidence that there is no clear dose-relationship but that RNAi is triggered from a specific threshold dose onward and might be maximal at an optimal dose (Turner et al., 2006; Niu et al., 2019). Third, high doses may cause sequence-unspecific effects as discussed above.

The endpoints to be recorded (lethal and sublethal) need to be selected based on the organism under investigation (and the reliability of the test system) and the gene that is targeted. While lethality is an obvious endpoint to be chosen, the consideration of sublethal endpoints such as growth or development time is recommended (Roberts et al., 2020). First, they may hint to unexpected off-target effects, second, they may cover for the fact that dsRNA is generally slow acting (Baum and Roberts, 2014) and that the process is typically not reaching $100 \%$ gene suppression (e.g., Bolognesi et al., 2012; Rangasamy and Siegfried, 2012), and third, they might address the fact that RNAi effects can be transgenerational, i.e., also affecting subsequent generations (Abdellatef et al., 2015). Sublethal endpoints are typically also recorded in the testing of chemical pesticides (e.g., Candolfi et al., 2000) and Bt proteins (De Schrijver et al., 2016; Roberts et al., 2020) even though mortality is the primary endpoint and often the results from testing sublethal endpoints are not reported in regulatory summaries. In any case, it is important to set decisionmaking criteria for every endpoint that is recorded. The duration of the study needs to be selected so that the measurement endpoints show a response should the test substance have an effect. Given the slow RNAi response, test probably need to be extended in duration compared to Bt Cry proteins (e.g., Bachman et al., 2013, 2016).

A key element of every laboratory study is the inclusion of a negative control treatment that allows to separate effects caused by the test system (e.g., the fitness of the test organisms, the suitability of the diet) from those caused by the test substance. Ideally, the negative control consists of a dsRNA molecule that targets a heterologous sequence absent from the insect's genome and that does thus not lead to specific gene silencing 
in the test species. This would control for any impact caused by a trigger of the RNAi cascade (sequence unspecific effects). Typical examples that have been used for this purpose include dsRNA targeting the green fluorescent protein (GFP) and $\beta$ glucuronidase (GUS). However, there is some evidence, that dsGFP causes adverse effects in arthropods when applied orally at very high doses (Nunes et al., 2013; Haller et al., 2019) or when injected (Jarosch and Moritz, 2012).

Positive controls, i.e., the addition of dsRNA molecules that are designed to silence a gene in the test insects can further help to interpret the study results as they provide evidence that the test system can detect a response and that the test species is sensitive to dietary RNAi. Positive controls have for example been deployed by Haller et al. (2019) when testing the effect of dsRNA targeting the vATPase-A of D. $v$. virgifera in two non-target ladybird beetles (Coleoptera: Coccinellidae). The data confirmed that two species of ladybirds are sensitive to dietary RNAi but that the non-target dsRNA molecule only had a weak effect. Another study using the same test substance in honey bees did not detect any effects in the positive control treatment raising doubts about the sensitivity of honey bees to dietary RNAi in general (Vélez et al., 2016).

\section{CONCLUSION}

In order to assess whether dsRNA-based pesticide sprays adversely affect valued non-target species in the agroecosystem, three questions need to be addressed: (1) Are the non-target arthropods exposed to biologically active dsRNA? (2) Do the non-target arthropods possess the RNAi machinery for dsRNA to trigger a response? and (3) are there sufficient sequence matches between the dsRNA molecule under consideration and the genome of the non-target arthropods to cause a sequencespecific effect.

While it is possible to make some generalizations regarding the level of exposure, potential uptake of dsRNA and the sensitivity to dietary RNAi for common non-target species in field crops, some open questions remain. For example it is still unclear to what extent the bioactive dsRNA molecule is transferred through the arthropod foodweb and whether penetration through the arthropod body wall is a relevant route of exposure for non-target species. Furthermore, it would be useful to evaluate whether the risk for certain arthropod taxa can be considered negligible because they digest dsRNA prior to ingestion and are thus unlikely to be exposed.

Concerning the hazard posed by dsRNA, it would be important to evaluate whether there are species or taxa that can be considered safe because they are insensitive to dietary RNAi in general (e.g., because they lack the dsRNA uptake mechanism). Also, uncertainty still exists regarding the sequence mismatches (and number thereof) between the targeted mRNA and the dsRNA that still allows for an RNAi response. There is evidence that genome information can help assess non-target effects. However, bioinformatics information is still lacking for most valued non-target arthropods. This information would help assist to predict non-target effects and select the most suitable (i.e., potentially sensitive) species to conduct feeding studies in the laboratory. Related to this, the power of bioinformatics for predicting non-target effects still needs to be further investigated before this information can be used to draw a conclusion about safety.

Consequently, it is essential to conduct feeding studies to assess whether the ingestion of dsRNA molecules poses a hazard to relevant non-target species. However, when planning the studies to be conducted in the laboratory with dsRNA-based pesticides, it would be necessary to add flexibility to the nontarget risk assessment framework used for chemical pesticides to allow a case-by-case assessment as is done for GE plants. A challenge remains the selection of the most appropriate negative and positive control treatments to ensure a robust interpretation of the study results and to minimize false negative and false positive results.

The main concern, however, is the fact that the carrier to which the dsRNA is bound or the formulation in which it is applied will be of ample importance as it not only affects the level at which non-target arthropods will be exposed, i.e., the stability and distribution of the active compound in the environment and in the insect gut and body, but also the extent of the RNAi response.

While there is a lot to profit from the experience with chemical pesticides and GE plants producing insecticidal proteins, insecticidal sprays based on dsRNA still pose some specific challenges to the non-target risk assessment.

\section{AUTHOR CONTRIBUTIONS}

JR and FW wrote and approved the manuscript.

\section{FUNDING}

JR and FW were funded by institutional funds. JR received funding from the OECD to participate in the workshop in Paris.

\section{ACKNOWLEDGMENTS}

This paper was given at the OECD Conference on Regulation of Externally Applied dsRNA-based Products for Management of Pests which took place at the OECD in Paris, France, on 10-12 April 2019, and which was sponsored by the OECD Co-operative Research Programme: Biological Resource Management for Sustainable Agricultural Systems whose financial support made it possible for JR to participate in the workshop. This manuscript summarizes *..*'s contribution during the OECD Conference on RNAi-based Pesticides, which was sponsored by the OECD Co-operative Research Programme: Biological Resource Management for Sustainable Agricultural Systems whose financial support made it possible for the author to participate in the conference.

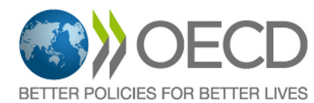




\section{REFERENCES}

Abdellatef, E., Will, T., Koch, A., Imani, J., Vilcinskas, A., and Kogel, K.-H. (2015). Silencing the expression of the salivary sheath protein causes transgenerational feeding suppression in the aphid Sitobion avenae. Plant Biotech. J. 13, 849-857. doi: $10.1111 /$ pbi.12322

Allen, M. L., and Walker, W. B. III (2012). Saliva of Lygus lineolaris digests double stranded ribonucleic acids. J. Insect Physiol. 58, 391-396. doi: 10.1016/j.jinsphys. 2011.12.014

Arimatsu, Y., Kotani, E., Sugimura, Y., and Furusawa, T. (2007). Molecular characterization of a cDNA encoding extracellular dsRNase and its expression in the silkworm, Bombyx mori. Insect Biochem. Mol. Biol. 37, 176-183. doi: 10.1016/j.ibmb.2006.11.004

Auer, C., and Frederick, R. (2009). Crop improvement using small RNAs: applications and predictive ecological risk assessment. Trends Biotechnol. 27, 644-651. doi: 10.1016/j.tibtech.2009.08.005

Bachman, P., Fischer, J., Song, Z., Urbanczyk-Wochniak, E., and Watson, G. (2020). Environmental fate and dissipation of applied dsRNA in soil, aquatic systems, and plants. Front. Plant Sci. 11:21. doi: 10.3389/fpls.2020.00021

Bachman, P. M., Bolognesi, R., Moar, W. J., Mueller, G. M., Paradise, M. S., Ramaseshadri, P., et al. (2013). Characterization of the spectrum of insecticidal activity of a double-stranded RNA with targeted activity against Western corn rootworm (Diabrotica virgifera virgifera LeConte). Transgenic Res. 22, 1207-1222. doi: 10.1007/s11248-013-9716-5

Bachman, P. M., Huizinga, K. M., Jensen, P. D., Mueller, G., Tan, J., Uffman, J. P., et al. (2016). Ecological risk assessment for DvSnf7 RNA: a plant-incorporated protectant with targeted activity against western corn rootworm. Regul. Toxicol. Pharmacol. 81, 77-88. doi: 10.1016/j.yrtph.2016.08.001

Barrett, K. L., Grandy, N., Harrison, E. G., Hassan, S., and Oomen, P. (eds) (1994). Guidance Document on Regulatory Testing Procedures for Pesticides with Nontarget Arthropods. ESCORT workshop (European Standard Characteristics of Non-Target Arthropod Regulatory Testing). Brussels: Society of Environmental Toxicology and Chemistry (SETAC) Europe.

Baum, J. A., Bogaert, T., Clinton, W., Heck, G. R., Feldmann, P., Ilagan, O., et al. (2007). Control of coleopteran insect pests through RNA interference. Nat. Biotechnol. 25, 1322-1326. doi: 10.1038/nbt1359

Baum, J. A., and Roberts, J. K. (2014). Progress towards RNAi-mediated insect pest management. Adv. Insect Physiol. 47, 249-295. doi: 10.1016/B978-0-12800197-4.00005-1

Belles, X. (2010). Beyond Drosophila: RNAi in vivo and functional genomics in insects. Annu. Rev. Entomol. 55, 111-128. doi: 10.1146/annurev-ento-112408085301

Bolognesi, R., Ramaseshadri, P., Anderson, J., Bachman, P., Clinton, W., Flannagan, R., et al. (2012). Characterizing the mechanism of action of doublestranded RNA activity against Western Corn Rootworm (Diabrotica virgifera virgifera LeConte). PLoS One 7:e47534. doi: 10.1371/journal.pone.0047534

Bona, A. C. D., Chitolina, R. F., Fermino, M. L., de Castro Poncio, L., Weiss, A., Lima, J. B. P., et al. (2016). Larval application of sodium channel homologous dsRNA restores pyrethroid insecticide susceptibility in a resistant adult mosquito population. Parasite Vector 9:397. doi: 10.1186/s13071-0161634-y

Brutscher, L. M., Daughenbaugh, K. F., and Flenniken, M. L. (2017). Virus and dsRNA-triggered transcriptional responses reveal key components of honey bee antiviral defense. Sci. Rep. 7:6448. doi: 10.1038/s41598-017-06623-z

Burand, J. P., and Hunter, W. B. (2013). RNAi: future in insect management. J. Invertebr. Pathol. 112, S68-S74. doi: 10.1016/j.jip.2012.07.012

Candolfi, M. P., Bakker, F., Cañez, V., Miles, M., Neumann, C., Pilling, E., et al. (1999). Sensitivity of non-target arthropods to plant protection products: could Typhlodromus pyri and Aphidius spp. be used as indicator species?. Chemosphere 39, 1357-1370. doi: 10.1016/S0045-6535(98) 00489-5

Candolfi, M. P., Barrett, K. L., Campbell, P., Forster, R., Grandy, N., Huet, M.-C., et al. (eds) (2001). Guidance Document on Regulatory Testing and Risk Assessment Procedures for Plant Protection Products with Non-target Arthropods. ESCORT 2 Workshop (European Standard Characteristics of NonTarget Arthropods Regulatory Testing), a joint BART, EPPO/CoE, OECD and IOBC Workshop organized in conjunction with SETAC-Europe and EC. Baoshan: SETAC Press.
Candolfi, M. P., Blümel, S., Foster, R., Bakker, F. M., Grimm, C., Hassan, S. A., et al. (eds) (2000). Guidelines to Evaluate Side-effects of Plant Protection Products to Non-target Arthropods. Gent: International Organization for Biological and Integrated Control of Noxious Animals and Weeds, West Palearctic Regional Section (IOBC/WPRS).

Carstens, K., Anderson, J., Bachman, P., De Schrijver, A., Dively, G., Federici, B., et al. (2012). Genetically modified crops and aquatic ecosystems: considerations for environmental risk assessment and non-target organism testing. Transgenic Res. 21, 813-842. doi: 10.1007/s11248-011-9569-8

Casacuberta, J. M., Devos, Y., du Jardin, P., Ramon, M., Vaucheret, H., and Nogué, F. (2015). Biotechnological uses of RNAi in plants: risk assessment considerations. Trends Biotechnol. 33, 145-147. doi: 10.1016/j.tibtech.2014.12. 003

Christiaens, O., Dzhambazova, T., Kostov, K., Arpaia, S., Joga, M. R., Urru, I., et al. (2018a). Literature review of baseline information on RNAi to support the environmental risk assessment of RNAi-based GM plants. Supporting Publication 2018: EN-1424. Parma: European Food Safety Authority (EFSA).

Christiaens, O., Prentice, K., Pertry, I., Ghislain, M., Bailey, A., Niblett, C., et al. (2016). RNA interference: a promising biopesticide strategy against the African Sweetpotato Weevil Cylas brunneus. Sci. Rep. 6:38836. doi: 10.1038/srep38836

Christiaens, O., Swevers, L., and Smagghe, G. (2014). DsRNA degradation in the pea aphid (Acyrthosiphon pisum) associated with lack of response in RNAi feeding and injection assay. Peptides 53, 307-314. doi: 10.1016/j.peptides.2013. 12.014

Christiaens, O., Tardajos, M. G., Martinez Reyna, Z. L., Dash, M., Dubruel, P., and Smagghe, G. (2018b). Increased RNAi efficacy in Spodoptera exigua via the formulation of dsRNA with guanylated polymers. Front. Physiol. 9:316. doi: $10.3389 /$ fphys.2018.00316

Cohen, A. C. (1995). Extra-oral digestion in predaceous terrestrial Arthropoda. Annu. Rev. Entomol. 40, 85-103. doi: 10.1146/annurev.en.40.010195.000505

Cohen, A. C. (1998). Solid-to-liquid feeding: the inside(s) story of extra-oral digestion in predaceous Arthropoda. Am. Entomol. 44, 103-117. doi: 10.1093/ ae/44.2.103

Cooper, A. M. W., Silver, K., Zhang, J., Park, Y., and Zhu, K. Y. (2019). Molecular mechanisms influencing efficiency of RNA interference in insects. Pest Manag. Sci. 75, 18-28. doi: 10.1002/ps.5126

Craig, W., Ndolo, D. O., and Tepfer, M. (2017). "A Strategy for integrating science into regulatory decision-making for GMOs," in Genetically Modified Organisms in Developing Countries. Risk Analysis and Governance, Chap. 3, eds A. A. Adenle, E. J. Morris, and D. J. Murphy (Cambridge, MA: Cambridge University Press), 26-38.

Dalakouras, A., Wassenegger, M., McMillan, J. N., Cardoza, V., Maegele, I., Dadami, E., et al. (2016). Induction of silencing in plants by high-pressure spraying of in vitro-synthesized small RNAs. Front. Plant Sci. 7:1327. doi: 10. 3389/fpls.2016.01327

Das, S., Debnath, N., Cui, Y., Unrine, J., and Palli, S. R. (2015). Chitosan, carbon quantum dot, and silica nanoparticle mediated dsRNA delivery for gene silencing in Aedes aegypti: a comparative analysis. ACS Appl. Mater. Interfaces 7, 19530-19535. doi: 10.1021/acsami.5b05232

Davis-Vogel, C., Van Allen, B., Van Hemert, J. L., Sethi, A., Nelson, M. E., and Sashital, D. G. (2018). Identification and comparison of key RNA interference machinery from western corn rootworm, fall armyworm, and southern green stink bug. PLoS One 13:e0203160. doi: 10.1371/journal.pone.0203160

De Schrijver, A., Devos, Y., De Clercq, P., Gathmann, A., and Romeis, J. (2016). Quality of laboratory studies assessing effects of Bt-proteins on non-target organisms: minimal criteria for acceptability. Transgenic Res. 25, 395-411. doi: 10.1007/s11248-016-9950-8

Devos, Y., Craig, W., Devlin, R. H., Ippolito, A., Leggatt, R. A., Romeis, J., et al. (2019). Using problem formulation for fit-for-purpose pre-market environmental risk assessments of regulated stressors. EFSA J. 17:e170708. doi: 10.2903/j.efsa.2019.e170708

Devos, Y., Romeis, J., Luttik, R., Maggiore, A., Perry, J. N., Schoonjans, R., et al. (2015). Optimising environmental risk assessments - Accounting for biodiversity and ecosystem services helps to translate broad policy protection goals into specific operational ones for environmental risk assessments. EMBO Rep. 16, 1060-1063. doi: 10.15252/embr.201540874

Dillin, A. (2003). The specifics of small interfering RNA specificity. Proc. Natl. Acad. Sci. U.S.A. 100, 6289-6291. doi: 10.1073/pnas. 1232238100 
Dubelman, S., Fischer, J., Zapata, F., Huizinga, K., Jiang, C., Uffman, J., et al. (2014). Environmental fate of double-stranded RNA in agricultural soils. PLoS One 9:e93155. doi: 10.1371/journal.pone.0093155

European Commission [EC] (2002). Guidance Document on Terrestrial Ecotoxicology under Council Directive 91/414/EEC. SANCO/10329/2002 rev 2 Final. Available online at: https:/ec.europa.eu/food/plant/pesticides/ approval_active_substances/guidance_documents_en (accessed January 20, 2020).

European Food Safety Authority (2015). Scientific opinion addressing the state of the science on risk assessment of plant protection products for non-target arthropods. EFSA panel on plant protection products and their residues (PPR). EFSA J. 13:3996. doi: 10.2903/j.efsa.2015.3996

European Food Safety Authority Scientific Committee (2016). Guidance to develop specific protection goals options for environmental risk assessment at EFSA, in relation to biodiversity and ecosystem services. EFSA J. 14:4499. doi: 10.2903/j. efsa.2016.4499

Fischer, J. R., Zapata, F., Dubelman, S., Mueller, G. M., Jensen, P. D., and Levine, S. L. (2016). Characterizing a novel and sensitive method to measure dsRNA in soil. Chemosphere 161, 319-324. doi: 10.1016/j.chemosphere.2016.07.014

Fischer, J. R., Zapata, F., Dubelman, S., Mueller, G. M., Uffman, J. P., Jiang, C., et al. (2017). Aquatic fate of a double-stranded RNA in a sediment-water system following an over-water application. Environ. Toxicol. Chem. 36, 727-734. doi: $10.1002 /$ etc. 3585

Flenniken, M. L., and Andino, R. (2013). Non-specific dsRNA-mediated antiviral response in the honey bee. PLoS One 8:e77263. doi: 10.1371/journal.pone. 0077263

Fletcher, S. J., Reeves, P. T., Tram Hoang, B., and Mitter, N. (2020). A perspective on RNAi-based biopesticides. Front. Plant Sci. 11:51. doi: 10.3389/fpls.2020.00051

Garbian, Y., Maori, E., Kalev, H., Shafir, S., and Sela, I. (2012). Bidirectional transfer of RNAi between honey bee and Varroa destructor: Varroa gene silencing reduces Varroa population. PLoS One 8:e1003035. doi: 10.1371/journal.ppat. 1003035

Garbutt, J. S., Bellés, X., Richards, E. H., and Reynolds, S. E. (2013). Persistence of double-stranded RNA in insect hemolymph as a potential determiner of RNA interference success: evidence from Manduca sexta and Blattella germanica. J. Insect Physiol. 59, 171-178. doi: 10.1016/j.jinsphys.2012.05.013

Gilioli, G., Schrader, G., Baker, R. H. A., Ceglarska, E., Kertéz, V. K., Lövei, G., et al. (2014). Environmental risk assessment for plant pests: a procedure to evaluate their impact on ecosystem services. Sci. Tot. Environ. 46, 475-486. doi: 10.1016/j.scitotenv.2013.08.068

Gillet, F.-X., Garcia, R. A., Macedo, L. L. P., Albuquerque, E. V. S., Solva, M. C. M., and Grossi-de-Sa, M. F. (2017). Investigating engineered ribonucleoprotein particles to improve oral RNAi delivery in crop insect pests. Front. Physiol. 8:256. doi: 10.3389/fphys.2017.00256

Gray, A. J. (2012). Problem formulation in environmental risk assessment for genetically modified crops: a practitioner's approach. Collect. Biosaf. Rev. 6, 10-65.

Haller, S., Widmer, F., Siegfried, B. D., Zhou, X., and Romeis, J. (2019). Responses of two ladybird beetle species (Coleoptera: Coccinellidae) to dietary RNAi. Pest Manag. Sci. 75, 2652-2662. doi: 10.1002/ps.5370

Hannon, G. J. (2002). RNA interference. Nature 418, 244-251.

He, B., Chu, Y., Yin, M., Müllen, K., An, C., and Shen, J. (2013). Fluorescent nanoparticle delivered dsRNA toward genetic control of insect pests. $A d v$. Mater. 25, 4580-4584. doi: 10.1002/adma.201301201

Head, G. P., Carroll, M. W., Evans, S. P., Rule, D. M., Willse, A. R., Clark, T. L., et al. (2017). Evaluation of SmartStax and SmartStax PRO maize against western corn rootworm and northern corn rootworm: efficacy and resistance management. Pest Manag. Sci. 73, 1883-1899. doi: 10.1002/ps.4554

Hilbeck, A., Weiss, G., Oehen, B., Römbke, J., Jänsch, S., Teichmann, H., et al. (2014). Ranking matrices as operational tools for the environmental risk assessment of genetically modified crops on non-target organisms. Ecol. Indic. 36, 367-381. doi: 10.1016/j.ecolind.2013.07.016

Hogervorst, P. A. M., van den Akker, H. C. M., Glandorf, D. C. M., Klaassen, P., van der Vlugt, C. J. B., and Westra, J. (2018). Assessment of Human Health and Environmental Risks of New Developments in Modern Biotechnology. RIVM Letter Report 2018-0089. Bilthoven: National Institute for Public Health and the Environment.
Hunter, W. B., Glick, E., Paldi, N., and Bextine, B. R. (2012). Advances in RNA interference: dsRNA treatment in trees and grapevines for insect pest suppression. Southwest. Entomol. 37, 85-87. doi: 10.3958/059.037.0110

Jarosch, A., and Moritz, R. F. A. (2012). RNA interference in honeybees: off-target effects caused by dsRNA. Apidologie 43, 128-138. doi: 10.1007/s13592-0110092-y

Katoch, R., Sethi, A., Thakur, N., and Murdock, L. L. (2013). RNAi for insect control: current perspective and future challenges. Appl. Biochem. Biotechnol. 171, 847-873. doi: 10.1007/s12010-013-0399-4

Khajuria, C., Ivashuta, S., Wiggins, E., Flagel, L., Moar, W., Pleau, M., et al. (2018). Development and characterization of the first dsRNA-resistant insect population from western corn rootworm, Diabrotica virgifera virgifera LeConte. PLoS One 13:e0197059. doi: 10.1371/journal.pone.0197059

Killiny, N., Hajeri, S., Tiwari, S., Gowda, S., and Stelinski, L. L. (2014). Doublestranded RNA uptake through topical application mediates silencing of five CYP4 genes and suppresses insecticide resistance in Diaphorina citri. PLoS One 9:e110536. doi: 10.1371/journal.pone.0110536

Kitzmann, P., Schwirz, J., Schmitt-Engel, C., and Bucher, G. (2013). RNAi phenotypes are influenced by the genetic background of the injected strain. BMC Genomics 14:5. doi: 10.1186/1471-2164-14-5

Koch, A., Biedenkopf, D., Furch, A., Weber, L., Rossbach, O., Abdellatef, E., et al. (2016). An RNAi-based control of Fusarium graminearum infections through spraying of long dsRNAs involves a plant passage and is controlled by the fungal silencing machinery. PLoS Pathog. 12:e1005901. doi: 10.1371/journal. ppat.1005901

Kunte, N., McGraw, E., Bell, S., Held, D., and Avila, L.-A. (2020). Prospects, challenges and current status of RNAi through insect feeding. Pest Manag. Sci. 76, 26-41. doi: 10.1002/ps.5588

Levine, S. L., Tan, J., Mueller, G. M., Bachman, P. M., Jensen, P. D., and Uffman, J. P. (2015). Independent action between DvSnf7 RNA and Cry3Bb1 protein in Southern Corn Rootworm, Diabrotica undecimpunctata howardi and Colorado Potato Beetle, Leptinotarsa decemlineata. PLoS One 10:e0118622. doi: 10.1371/ journal.pone.0118622

Li, H., Guan, R., Guo, H., and Miao, X. (2015a). New insights into an RNAi approach for plant defence against piercing-sucking and stem-borer insect pests. Plant Cell Environ. 38, 2277-2285. doi: 10.1111/pce.12546

Li, H., Khajuria, C., Rangasamy, M., Gandra, P., Fitter, M., Geng, C., et al. (2015b). Long dsRNA but not siRNA initiates RNAi in western corn rootworm larvae and adults. J. Appl. Entomol. 139, 432-445. doi: 10.1111/jen.12224

Li, Y., Zhang, Q., Liu, Q., Meissle, M., Yang, Y., Wang, Y., et al. (2017). Bt rice in China-focusing the non-target risk assessment. Plant Biotechnol. J. 15, 1340-1345. doi: 10.1111/pbi.12720

Lin, Y.-H., Huang, J.-H., Liu, Y., Belles, X., and Lee, H.-J. (2017). Oral delivery of dsRNA lipoplexes to German cockroach protects dsRNA from degradation and induces RNAi response. Pest Manag. Sci. 73, 960-966. doi: 10.1002/ps.4407

Liu, J., Smagghe, G., and Swevers, L. (2013). Transcriptional response of BmToll91 and RNAi machinery genes to exogenous dsRNA in the midgut of Bombyx mori. J. Insect Physiol. 59, 646-654. doi: 10.1016/j.jinsphys.2013.03.013

Liu, J., Swevers, L., Iatrou, K., Huvenne, H., and Smagghe, G. (2012). Bombyx mori DNA/RNA non-specific nuclease: expression of isoforms in insect culture cells, subcellular localization and functional assays. J. Insect Physiol. 58, 1166-1176. doi: 10.1016/j.jinsphys.2012.05.016

Liu, S., Jaouannet, M., Dempsey, D. A., Imani, J., Coustau, C., and Kogel, K.-H. (2020). RNA-based technologies for insect control in plant production. Biotech. Adv. 39:107463. doi: 10.1016/j.biotechadv.2019.107463

Lundgren, J. G. (2009). Relationship of Natural Enemies and Non-prey Foods. Cham: Springer Science + Business Media B.V.

Maltby, L. L., Duke, C., and van Wensem, J. (2017a). Ecosystem services, environmental stressors and decision making: how far have we got? Integr. Environ. Assess. Manag. 13, 38-40. doi: 10.1002/ieam.1796

Maltby, L. L., Jackson, M., Whale, G., Brown, A. R., Hamer, M., Solga, A., et al. (2017b). Is an ecosystem services-based approach developed for setting speci?c protection goals for plant protection products applicable to other chemicals? Sci. Total Environ. 580, 1222-1236. doi: 10.1016/j.scitotenv.2016.12.083

Meissle, M., Álvarez-Alfageme, F., Malone, L. A., and Romeis, J. (2012). Establishing a Database of Bio-Ecological Information on Non-Target Arthropod Species to Support the Environmental Risk Assessment of Genetically Modified 
Crops in the EU. Supporting Publication 2012:EN-334. Parma: European Food Safety Authority (EFSA).

Millennium Ecosystem Assessment [MEA] (2005). Ecosystems and Human WellBeing: Synthesis. Washington, DC: MEA.

Miller, S. C., Miyata, K., Brown, S. J., and Tomoyasu, Y. (2012). Dissecting systemic RNA interference in the red flour beetle Tribolium castaneum: parameters affecting the efficiency of RNAi. PLoS One 7:e47431. doi: 10.1371/journal.pone. 0047431

Mitter, N., Worrall, E. A., Robinson, K. E., Li, P., Jain, R. G., Taochy, C., et al. (2017). Clay nanosheets for topical delivery of RNAi for sustained protection against plant viruses. Nat. Plants 3:16207. doi: 10.1038/nplants.2016.207

Nandety, R. S., Kuo, Y. W., Nouri, S., and Falk, B. W. (2015). Emerging strategies for RNA interference (RNAi) applications in insects. Bioengineered 6, 8-19. doi: $10.4161 / 21655979.2014 .979701$

Nienstedt, K. M., Brock, T. C. M., van Wensem, J., Montforts, W., Hart, A., Aagaard, A., et al. (2012). Development of a framework based on an ecosystem services approach for deriving specific protection goals for environmental risk assessment of pesticides. Sci. Total Environ. 415, 31-38. doi: 10.1016/j.scitotenv. 2011.05.057

Niu, J., Shen, G., Christiaens, O., Smagghe, G., He, L., and Wang, J. (2018). Beyond insects: current status, achievements and future perspectives of RNAi in mite pests. Pest Manag. Sci. 74, 2680-2687. doi: 10.1002/ps.5071

Niu, J., Yang, W.-J., Tian, Y., Fan, J.-Y., Ye, C., Shang, F., et al. (2019). Topical dsRNA delivery induces gene silencing and mortality in the pea aphid. Pest Manag. Sci. 75, 2873-2881. doi: 10.1002/ps.5457

Nunes, F. M. F., Aleixo, A. C., Barchuk, A. R., Bomtorin, A. D., Grozinger, C. M., and Simões, Z. L. P. (2013). Non-target effects of green fluorescent protein (GFP)-derived double-stranded RNA (dsRNA-GFP) used in honey bee RNA interference (RNAi) assays. Insects 4, 90-103. doi: 10.3390/insects 4010090

Pan, H., Xu, L., Noland, J. E., Li, H., Siegfried, B. D., and Zhou, X. (2016). Assessment of potential risks of dietary RNAi to a soil micro-arthropod, Sinella curviseta Brook (Collembola: Entomobryidae). Front. Plant Sci. 7:1028. doi: 10.3389/fpls.2016.01028

Parker, K. M., Borrero, V. B., van Leeuwen, D. M., Lever, M. A., Mateescu, B., and Sander, M. (2019). Environmental fate of RNA interference pesticides: adsorption and degradation of double-stranded RNA molecules in agricultural soils. Environ. Sci. Technol. 53, 3027-3036. doi: 10.1021/acs.est.8b05576

Piot, N., Snoeck, S., Vanlede, M., Smagghe, G., and Meeus, I. (2015). The effect of oral administration of dsRNA on viral replication and mortality in Bombus terrestris. Viruses 7, 3172-3185. doi: 10.3390/v7062765

Powell, M., Pyati, P., Cao, M., Bell, H., Gatehouse, J. A., and Fitches, E. (2017). Insecticidal effects of dsRNA targeting the Diap1 gene in dipteran pests. Sci. Rep. 7:15147. doi: 10.1038/s41598-017-15534-y

Prentice, K., Christiaens, O., Pertry, O., Bailey, A., Niblett, C., Ghislain, M., et al. (2017). RNAi-based gene silencing through dsRNA injection or ingestion against the African sweet potato weevil Cylas puncticollis (Coleoptera: Brentidae). Pest Manag. Sci. 73, 44-52. doi: 10.1002/ps.4337

Pridgeon, J. W., Zhao, L., Becnel, J. J., Strickman, D. A., Clark, G. G., and Linthicum, K. J. (2008). Topically applied AaeIAP1 double-stranded RNA kills female adults of Aedes aegypti. J. Med. Entomol. 45, 414-420. doi: 10.1093/jme/ tjv192

Rangasamy, M., and Siegfried, B. D. (2012). Validation of RNA interference in western corn rootworm Diabrotica virgifera virgifera LeConte (Coleoptera: Chrysomelidae) adults. Pest Manag. Sci. 68, 587-591. doi: 10.1002/ps.2301

Raybould, A. (2006). Problem formulation and hypothesis testing for environmental risk assessments of genetically modified crops. Environ. Biosaf. Res. 5, 119-125. doi: 10.1051/ebr:2007004

Raybould, A., and Burns, A. (2020). Problem formulation for off-target effects of externally applied double-stranded RNA-based products for pest-control. Front. Plant Sci. 11:424. doi: 10.3389/fpls.2020.00424

Raybould, A., Holt, K., and Kimber, I. (2019). Using problem formulation to clarify the meaning of weight of evidence and biological relevance in environmental risk assessments for genetically modified crops. GM Crops Food 10, 63-76. doi: 10.1080/21645698.2019.1621615

Riedel, J., Romeis, J., and Meissle, M. (2016). Update and Expansion of the Database of Bio-Ecological Information on Non-Target Arthropod Species Established to Support the Environmental Risk Assessment of Genetically Modified Crops in the EU. Supporting Publication 2016:EN-956. Parma: European Food Safety Authority (EFSA).

Roberts, A. F., Boeckman, C. J., Mühl, M., Romeis, J., Teem, J. L., Valicente, F. H. H., et al. (2020). Sublethal endpoints in non-target organism testing for insect active GE crops. Front. Bioeng. Biotechnol. doi: 10.3389/fbioe.2020.00556

Roberts, A. F., Devos, Y., Lemgo, G. N. Y., and Zhou, X. (2015). Biosafety research for non-target organism risk assessment of RNAi-based GE plants. Front. Plant Sci. 6:958. doi: 10.3389/fpls.2015.00958

Römbke, J., Jänsch, S., Meier, M., Hilbeck, A., Teichmann, H., and Tappeser, B. (2010). General recommendations for soil ecotoxicological tests suitable for the environmental risk assessment of genetically modified plants. Integr. Environ. Assess. Manag. 6, 287-300. doi: 10.1897/IEAM.2009-043.1

Romeis, J., Hellmich, R. L., Candolfi, M. P., Carstens, K., De Schrijver, A., Gatehouse, A. M. R., et al. (2011). Recommendations for the design of laboratory studies on non-target arthropods for risk assessment of genetically engineered plants. Transgenic Res. 20, 1-22. doi: 10.1007/s11248-010-9446-X

Romeis, J., Meissle, M., Álvarez-Alfageme, F., Bigler, F., Bohan, D. A., Devos, Y., et al. (2014). Potential use of an arthropod database to support the nontarget risk assessment and monitoring of transgenic plants. Transgenic Res. 23, 995-1013. doi: 10.1007/s11248-014-9791-2

Romeis, J., Raybould, A., Bigler, F., Candolfi, M. P., Hellmich, R. L., Huesing, J. E., et al. (2013). Deriving criteria to select arthropod species for laboratory tests to assess the ecological risks from cultivating arthropod-resistant genetically engineered crops. Chemosphere 90, 901-909. doi: 10.1016/j.chemosphere.2012. 09.035

San Miguel, K., and Scott, J. G. (2016). The next generation of insecticides: dsRNA is stable as a foliar-applied insecticide. Pest Manag. Sci. 72, 801-809. doi: 10. 1002/ps.4056

Sanvido, O., Romeis, J., Gathmann, A., Gielkens, M., Raybould, A., and Bigler, F. (2012). Evaluating environmental risks of genetically modified crops Ecological harm criteria for regulatory decision-making. Environ. Sci. Policy 15, 82-91. doi: 10.1016/j.envsci.2011.08.006

Scott, J. G., Michel, K., Bartholomay, L. C., Siegfried, B. D., Hunter, W. B., Smagghe, G., et al. (2013). Towards the elements of successful insect RNAi. J. Insect Physiol. 59, 1212-1221. doi: 10.1016/j.jinsphys.2013.08.014

Spit, J., Philips, A., Wynant, N., Santos, D., Plaetinck, G., and Vanden Broeck, J. (2017). Knockdown of nuclease activity in the gut enhances RNAi efficiency in the Colorado potato beetle, Leptinotarsa decemlineata, but not in the desert locust, Schistocerca gregaria. Insect Biochem. Mol. Biol. 81:103e116. doi: 10.1016/ j.ibmb.2017.01.004

Sugahara, R., Tanaka, S., Jouraku, A., and Shiotsuki, T. (2017). Geographic variation in RNAi sensitivity in the migratory locust. Gene 605, 5-11. doi: 10.1016/j.gene.2016.12.028

Taning, C. N. T., Arpaia, S., Christiaens, O., Dietz-Pfeilstetter, A., Jones, H., Mezzetti, B., et al. (2020). RNA-based biocontrol compounds: current status and perspectives to reach the market. Pest Manag. Sci. 76, 841-845. doi: 10.1002/ps. 5686

Taning, C. N. T., Christiaens, O., Berkvens, N., Casteels, H., Maes, M., and Smagghe, G. (2016). Oral RNAi to control Drosophila suzukii: laboratory testing against larval and adult stages. J. Pest Sci. 89, 803-814. doi: 10.1007/s10340-0160736-9

Tenllado, F., Llave, C., and Diaz-Ruiz, J. R. (2004). RNA interference as a new biotechnological tool for the control of virus diseases in plants. Virus Res. 102, 85-96. doi: 10.1016/j.virusres.2004.01.019

Terenius, O., Papanicolaou, A., Garbutt, J. S., Eleftherianos, I., Huvenne, H., Kanginakudru, S., et al. (2011). RNA interference in Lepidoptera: an overview of successful and unsuccessful studies and implications for experimental design. J. Insect Physiol. 57, 231-245. doi: 10.1016/j.jinsphys.2010.11.006

Todd, J. H., Ramankutty, P., Barraclough, E. I., and Malone, L. A. (2008). A screening method for prioritizing non-target invertebrates for improved biosafety testing of transgenic crops. Environ. Biosafety Res. 7, 35-56. doi: 10.1051/ebr:2008003

Turner, C. T., Davy, M. W., MacDiarmid, R. M., Plummer, K. M., Birch, N. P., and Newcomb, R. D. (2006). RNA interference in the light brown apple moth, Epiphyas postvittana (Walker) induced by double-stranded RNA feeding. Insect Mol. Biol. 15, 383-391. doi: 10.1111/j.1365-2583.2006. 00656.x 
US EPA (2014). RNAi Technology: Program Formulation for Human Health and Ecological Risk Assessment. Scientific Advisory Panel Minutes No.201402 (Arlington, VA). Available online at: https://www.epa.gov/sites/production/ files/2015-06/documents/012814minutes.pdf (accessed January 20, 2020).

Vélez, A. M., Jurzenski, J., Matz, N., Zhou, X., Wang, H., Ellis, M., et al. (2016). Developing an in vivo toxicity assay for RNAi risk assessment in honey bees, Apis mellifera L. Chemosphere 144, 1083-1090. doi: 10.1016/j.chemosphere. 2015.09.068

Vogel, E., Snatos, D., Mingels, L., Verdonckt, T.-W., and Broeck, J. V. (2019). RNA interference in insects: protecting beneficials and controlling pests. Front. Physiol. 9:1912. doi: 10.3389/fphys.2018.01912

Vogt, H. (2000). Sensitivity of non-target arthropods species to plant protection products according to laboratory results of the IOBC WG "Pesticides and beneficial organisms". IOBC/WPRS Bull. 23, 3-15.

Walter, A., Bechsgaard, J., Scavenius, C., Dyrlund, T. S., Sanggaard, K. W., Enghild, J. J., et al. (2017). Characterisation of protein families in spider digestive fluids and their role in extra-oral digestion. BMC Genomics 18:600. doi: 10.1186/ s12864-017-3987-9

Wang, K., Peng, Y., Pu, J., Fu, W., Wang, J., and Han, Z. (2016). Variation in RNAi efficacy among insect species is attributable to dsRNA degradation in vivo. Insect Biochem. Mol. Biol. 77, 1-9. doi: 10.1016/j.ibmb.2016. 07.007

Wang, Y., Zhang, H., Li, H., and Miao, X. (2011). Second-generation sequencing supply an effective way to screen RNAi targets in large scale for potential application in pest insect control. PLoS One 6:e18644. doi: 10.1371/journal. pone. 0018644

Whangbo, J. S., and Hunter, C. P. (2008). Environmental RNA interference. Trends Genet. 24, 297-305. doi: 10.1016/j.tig.2008.03.007

Whyard, S., Singh, A. D., and Wong, S. (2009). Ingested double-stranded RNAs can act as species-specific insecticides. Insect Biochem. Mol. Biol. 39, 824-832. doi: 10.1016/j.ibmb.2009.09.007

Wynant, N., Santos, D., Verdonck, R., Spit, J., Van Wielendaele, P., and Vanden Broeck, J. (2014). Identification, functional characterization and phylogenetic analysis of double stranded RNA degrading enzymes present in the gut of the desert locust, Schistocerca gregaria. Insect Biochem. Mol. Biol. 46, 1-8. doi: 10.1016/j.ibmb.2013.12.008

Xue, X. Y., Mau, Y. B., Tao, X. Y., Huang, Y. P., and Chen, X. Y. (2012). New approaches to agricultural insect pest control based on RNA interference. Adv. Insect Physiol. 42, 73-117. doi: 10.1016/B978-0-12-387680-5. 00003-3

Yu, N., Christiaens, O., Liu, J., Niu, J., Cappelle, K., Caccia, S., et al. (2013). Delivery of dsRNA for RNAi in insects: an overview and future directions. Insect Sci. 20, 4-14. doi: 10.1111/j.1744-7917.2012.01534.x

Zhang, J., Khan, S. A., Heckel, D. G., and Bock, R. (2017). Next-generation insect-resistant plants: RNAi-mediated crop protection. Trends Biotechnol. 35 , 871-882. doi: 10.1016/j.tibtech.2017.04.009

Zhang, X., Zhang, J., and Zhu, K. Y. (2010). Chitosan/double-stranded RNA nanoparticle-mediated RNA interference to silence chitin synthase genes through larval feeding in the African malaria mosquito (Anopheles gambiae). Insect Mol. Biol. 19, 683-693. doi: 10.1111/j.1365-2583.2010.01029.x

Zheng, Y., Hu, Y., Yan, S., Zhou, H., Song, D., Yin, M., et al. (2019). A polymer/detergent formulation improves dsRNA penetration through the body wall and RNAi-induced mortality in the soybean aphid Aphis glycines. Pest Manag. Sci. 75, 1993-1999. doi: 10.1002/ps.5313

Zhou, X., Wheeler, M. M., Oi, F. M., and Scharf, M. E. (2008). RNA interference in the termite Reticulitermes flavipes through ingestion of double-stranded RNA. Insect Biochem. Mol. Biol. 38, 805-815. doi: 10.1016/j.ibmb.2008.05.005

Zhu, Y.-C., Yao, J., and Luttrell, R. (2016). Identification of genes potentially responsible for extra-oral digestion and overcoming plant defense from salivary glands of the tarnished plant bug (Hemiptera: Miridae) using cDNA sequencing. J. Insect Sci. 16:60. doi: 10.1093/jisesa/iew041

Disclaimer: The opinions expressed and arguments employed in this paper are the sole responsibility of the authors and do not necessarily reflect those of the OECD or of the governments of its Member countries.

Conflict of Interest: The authors declare that the research was conducted in the absence of any commercial or financial relationships that could be construed as a potential conflict of interest.

Copyright (c) 2020 Romeis and Widmer. This is an open-access article distributed under the terms of the Creative Commons Attribution License (CC BY). The use, distribution or reproduction in other forums is permitted, provided the original author(s) and the copyright owner(s) are credited and that the original publication in this journal is cited, in accordance with accepted academic practice. No use, distribution or reproduction is permitted which does not comply with these terms. 